\title{
FÓSSEIS EM UMA FRENTE DE EXTRAÇÃO DE MÁRMORE? ANÁLISES TAFONÔMICA E PALEOICNOLÓGICA DE MAMÍFEROS DE GRANDE PORTE DO QUATERNÁRIO DO ESPÍRITO SANTO, BRASIL
}

\author{
RODRIGO VENTURA GERMANO, RICHARD BUCHMANN \& TAISSA RODRIGUES \\ Laboratório de Paleontologia, Departamento de Ciências Biológicas, Centro de Ciências Humanas e Naturais, \\ Universidade Federal do Espírito Santo, Av. Fernando Ferrari, 514, 29075-910, Vitória, ES, Brasil. \\ rodrigogermano16@gmail.com,richard_buchmann@hotmail.com,taissa.rodrigues@ufes.br
}

\begin{abstract}
Fossils on a marble extraction front? Taphonomic and paleoicnological analyzes of large mammals of the Quaternary of Espírito Santo, Brazil. The occurrence of fossil mammals in the State of Espírito Santo is rare, with only two records, both reported to sediments localized within marble quarries in the district of Itaoca, in the Municipality of Cachoeiro de Itapemirim. The first record dates from 1978, when fossils of Eremotherium and gomphotheres were collected together with other vertebrate fossils and posteriorly described. The second dates from 1983, with the description of fossils of Eremotherium in an abstract. Part of this latter finding is housed at the Federal University of Espírito Santo (UFES) and represents the only fossil mammals from the State that are currently available for study. It comprises 15 specimens, including cranial and post-cranial material. From these, eight can be referred to Eremotherium, one to Toxodontinae, one to Notiomastodon, and the others to large-bodied mammals. Fossils of Eremotherium and of indeterminate mammals are compatible with the presence of one giant ground sloth individual. Taphonomic and paleoichnological analyses of this supposed individual show that after death carnivores scavenged the carcass and that the bones were exposed to weathering for a relatively short time until they were transported by a hydraulic flow to a crevice, thus explaining the unusual finding of fossils in this particular outcrop.
\end{abstract}

Keywords: Eremotherium, Notiomastodon, Toxodontinae, southeastern Brazil, taphonomy, Praedichnia.

RESUMO - A ocorrência de mamíferos fósseis no Estado do Espírito Santo é rara, com apenas dois registros, ambos ocorrendo em sedimentos localizados dentro de frentes de extração de mármore no distrito de Itaoca, no Município de Cachoeiro de Itapemirim. O primeiro registro ocorreu em 1978, quando fósseis de Eremotherium e gonfotérios foram coletados com os de outros vertebrados e posteriormente descritos. O segundo data de 1983, com a descrição de fósseis de Eremotherium em um resumo. Parte deste último achado está tombado na Universidade Federal do Espírito Santo (UFES) e representa os únicos mamíferos fósseis do Estado que atualmente estão disponíveis para estudo. Consiste em 15 espécimes, incluindo material craniano e pós-craniano. Destes, oito podem ser atribuídos a Eremotherium, um a Toxodontinae, um a Notiomastodon, e os demais a mamíferos de grande porte. Os fósseis de Eremotherium e os de mamíferos indeterminados são compatíveis com a presença de um indivíduo de preguiça-gigante. Análises tafonômicas e paleoicnológicas dos fósseis deste suposto indivíduo mostram que, após a morte, carnívoros necrófagos atuaram sobre a carcaça e que os ossos ficaram expostos ao intemperismo por um tempo relativamente curto até que eles foram transportados por um fluxo hidráulico para uma fenda, explicando assim o achado incomum de fósseis neste afloramento em particular.

Palavras-chave: Eremotherium, Notiomastodon, Toxodontinae, sudeste do Brasil, tafonomia, Praedichnia.

\section{INTRODUÇÃO}

Fósseis continentais do Quaternário do Brasil são encontrados em depósitos fluviais, lacustres, aluviais, costeiros e, principalmente, em tanques e cavernas (Bergqvist \& Almeida, 2004). Os depósitos de tanques naturais são comuns no nordeste brasileiro, sendo formados por sedimentos depositados em depressões em inselbergs (AraújoJúnior et al., 2013). As cavernas possuem um extenso registro fossilífero, com espécimes frequentemente encontrados em condutos preenchidos com sedimentos de origem siliciclástica (Cartelle, 1992). Depósitos em cavernas são frequentemente encontrados nas regiões Sudeste e Nordeste do Brasil (Cartelle, 1992).
O Espírito Santo encontra-se inserido em um cinturão de rochas metamórficas e ígneas com raros afloramentos de rochas sedimentares quaternárias continentais (Albino et al., 2006; Vieira \& Menezes, 2015). Essas características explicam a raridade de encontrar fósseis de vertebrados no Estado, cujos achados, até o momento pontuais, deram-se graças a uma incomum presença de sedimentos contendo fósseis entre rochas metamórficas.

Mamíferos fósseis do Pleistoceno do Espírito Santo foram relatados por Paula Couto (1978), que descreveu restos de Eremotherium, Gomphotheriidae, Dasyproctidae e fragmentos ósseos de Amphibia, Reptilia e Neornithes que foram coletados em 1974 na Serra da Gironda, no distrito de Itaoca, Município de Cachoeiro de Itapemirim. Estes 
fósseis foram encontrados em um conglomerado composto por seixos de mármore em uma matriz de argila, ou marga, localizado em uma pedreira (Indústria de Mármore Italva Ltda.) e foram tombados no Museu Nacional, Universidade Federal do Rio de Janeiro (MN-UFRJ) (Paula Couto, 1978). Em 1982, fósseis de Eremotherium foram encontrados em outra frente de extração de mármore, também no distrito de Itaoca, e sucintamente descritos (Souza Cunha et al., 1983). O presente trabalho tem como objetivo a descrição deste material, incluindo a interpretação de suas feições tafonômicas e paleoicnológicas, buscando contribuir para o entendimento sobre as condições que levaram a este raro achado para o Estado.

\section{MATERIAL E MÉTODOS}

\section{Material e contexto geológico}

O material aqui analisado consiste em uma porção posterior do crânio, um segmento do dentário direito e dois do dentário esquerdo, um fragmento de dente, um centro vertebral de uma vértebra cervical, uma vértebra torácica, parte do arco neural de uma vértebra não identificada, uma costela apresentando o tubérculo e uma porção da diáfise, duas costelas representadas por parte das diáfises, uma porção distal da clavícula esquerda, uma porção distal de um fêmur direito, uma porção distal da tíbia esquerda e uma diáfise de um osso longo, possivelmente uma ulna. Cada espécime encontra-se tombado sob o número UFES-Pal-001, seguido de uma letra minúscula. Medidas foram tomadas com o auxílio de um paquímetro ou com uma fita métrica e referem-se ao tamanho dos fragmentos, como preservados.

O material foi coletado na localidade Alto Moledo, no distrito de Itaoca, no Município de Cachoeiro de Itapemirim, em uma frente de extração de mármore realizada em uma jazida da empresa Mármore Salviano Ltda. (MARSAL) (Souza Cunha et al., 1983; Salviano da Costa, 1991) (Figura 1). Segundo informações dos operários da empresa, o material aqui descrito foi encontrado depositado em uma fenda formada entre calcários calcíticos e dolomíticos e parcialmente soterrado por argila (Souza Cunha et al., 1983). A geomorfologia do local é muito acidentada, apresentando algumas escarpas nas faixas granito-gnáissicas e fendas nas áreas calcárias (Salviano da Costa, 1991). A drenagem corresponde ao padrão dendrítico nas áreas granitognáissicas e retangular nas calcárias, sendo esta segunda característica de terrenos densamente fraturados (Salviano da Costa, 1991).

Dados a respeito da posição e orientação dos fósseis, bem como quanto às dimensões exatas da fenda, não foram coletados. No entanto, reconstruções do depósito foram realizadas de acordo com informações das professoras Sonia Zannoti Xavier e Rosa Maria Senna Melo, da Universidade Federal do Espírito Santo (UFES), que estiveram no local para realizar o resgate do material e que relataram que ele estava desarticulado; porém dados mais precisos sobre isso não foram obtidos e, portanto, aqui consideraremos o grau de desarticulação como desconhecido (Figura 2). Após o resgate, o material não foi submetido a procedimentos de preparação

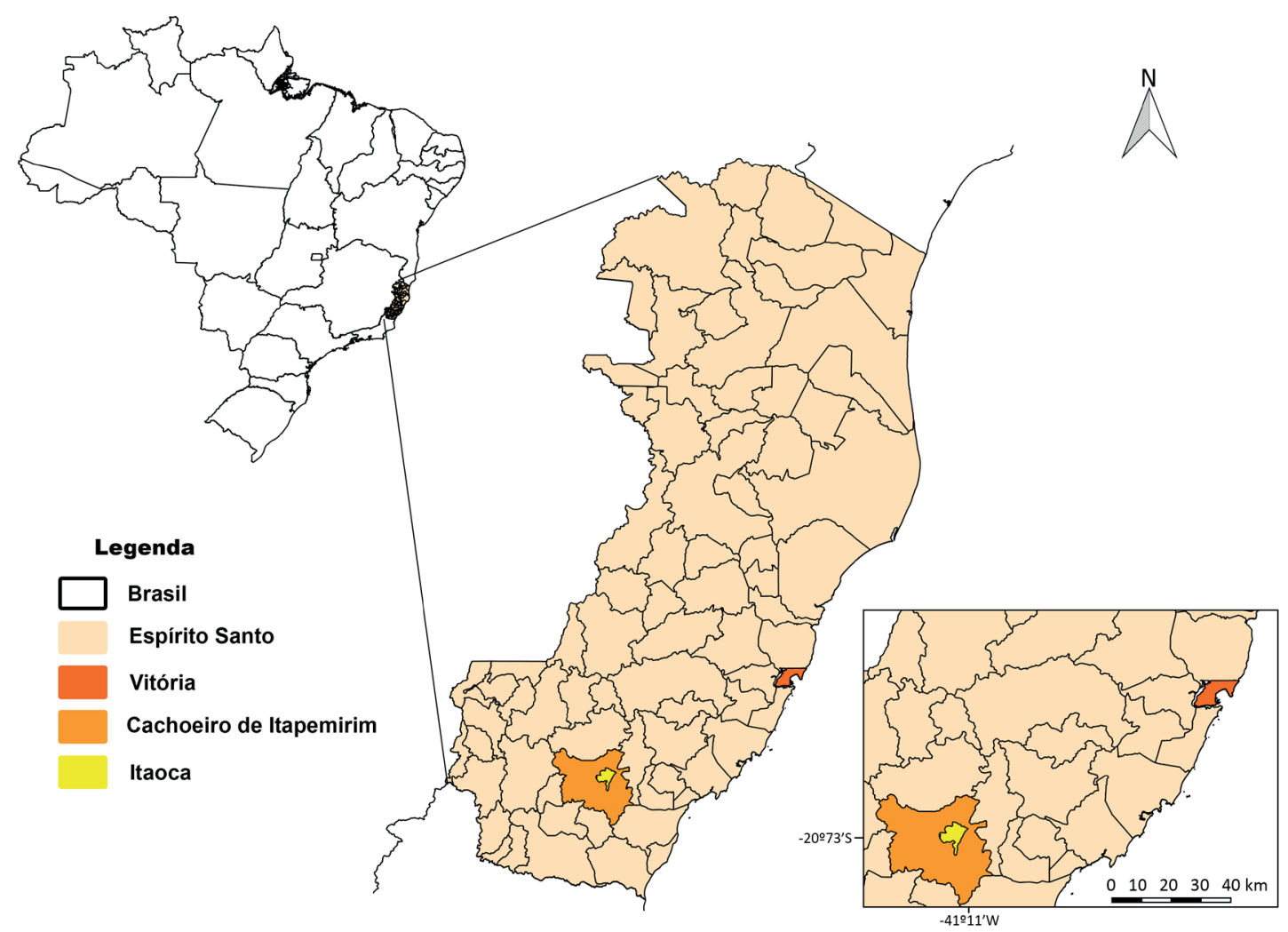

Figura 1. Localização do distrito de Itaoca, no Município de Cachoeiro de Itapemirim, Espírito Santo, Brasil.

Figure 1. Location of the Itaoca district, in the Municipality of Cachoeiro de Itapemirim, Espírito Santo, Brazil. 
e foi brevemente analisado pelo paleontólogo Fausto Luiz de Souza Cunha do MN-UFRJ e pelas professoras supracitadas (Souza Cunha et al., 1983). Os espécimes recuperados foram separados em três partes, das quais duas foram tombadas em coleções públicas: no MN-UFRJ e na UFES. A terceira parte foi guardada em uma coleção particular em Cachoeiro de Itapemirim (De Paula, 2016). Dadas as incertezas sobre a situação atual dos fósseis que foram atingidos no incêndio que acometeu o Museu Nacional em setembro de 2018, os únicos elementos do referido material que podem ser presentemente analisados são aqueles tombados na Coleção de Paleontologia do Departamento de Ciências Biológicas da UFES, em Vitória - ES.

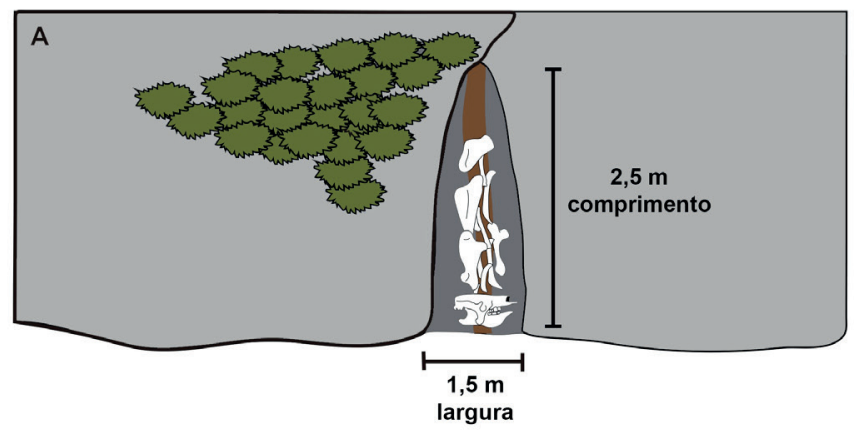

B

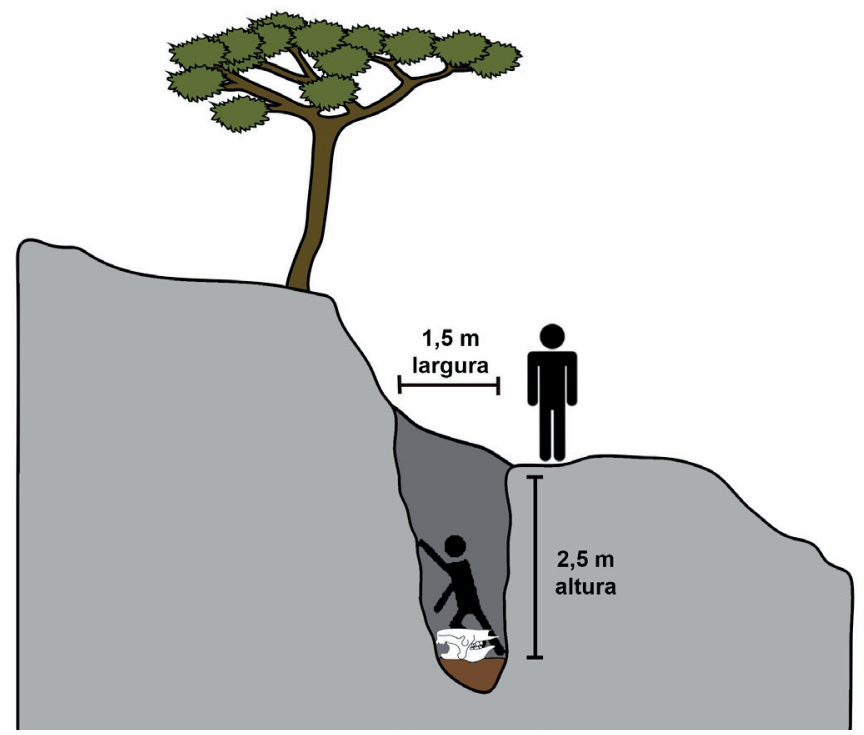

Figura 2. Desenho esquemático da fenda formada entre rochas metamórficas onde os fósseis foram recuperados (as ilustrações não levam em consideração a integridade física nem a distribuição espacial dos ossos). Pessoas de 1,80 m são representadas na figura. A, vista aérea evidenciando o comprimento e a largura aproximados da fenda. B, vista lateral evidenciando a profundidade e a largura aproximadas da fenda.

Figure 2. Scheme of the crevice formed between metamorfic rocks where the fossils were recovered (illustrations do not consider physical integrity nor special distribution of the bones). People with $1.80 \mathrm{~m}$ are represented in the figure. A, aerial view showing the approximate length and width of the crevice. $\mathbf{B}$, side view showing the approximate depth and width of the crevice.

\section{Análise tafonômica macroscópica}

Dado que a maior parte dos fósseis foi identificada como pertencente a Eremotherium laurillardi, a fim de estimar o número de indivíduos presentes desta espécie foram determinados o Número de Espécimes Identificados por táxon (NISP) e o Número Mínimo de Indivíduos (MNI) seguindo Lyman (1994). Com o objetivo de investigar se os animais morreram dentro da fenda na qual os fósseis foram encontrados, ou se foram transportados para ela após a morte, os seguintes parâmetros foram avaliados: (i) integridade física (completo, parcial e fragmento; segundo Behrensmeyer, 1991); (ii) estágios de intemperismo, medidos pela intensidade das marcas de dessecação (Behrensmeyer, 1978); (iii) estágios de abrasão (Shipman, 1981); (iv) estágios de incrustação (Maldonado et al., 2016); (v) classificação do tipo de assembleia fossilífera (Araújo-Júnior, 2016); e (vi) Índice de Transporte Fluvial (Fluvial Transport Index, FTI) (Frison \& Todd, 1986), o qual, segundo Araújo-Júnior et al. (2012), se mostra mais adequado do que aquele proposto por Voorhies (1969) para elementos ósseos pertencentes a indivíduos da megafauna. Interpretações paleoicnológicas foram realizadas com base nos critérios descritos por Haynes (1980), Dominato et al. (2011) e Araújo-Júnior et al. (2017).

\section{PALEONTOLOGIA SISTEMÁTICA}

\author{
Ordem XENARTHRA Cope, 1889 \\ Superfamília MEGATHERIOIDEA Gray, 1821 \\ Família MEGATHERIIDAE Owen, 1843 \\ Subfamília MEGATHERIINAE Gill, 1872
}

Eremotherium Spillmann, 1948

\section{Eremotherium laurillardi (Lund, 1842) \\ (Figuras 3-6)}

Descrição anatômica. UFES-Pal-001e consiste em uma parte da região posterior do crânio com 17,2 cm de comprimento e 14,7 cm de altura (Figura 3). Essa porção é curta e possui muitos forames nutritivos. Em sua vista lateral esquerda observa-se a porção ectotimpânica do osso temporal, incluindo o anel timpânico e a abertura do meato acústico externo. Essa abertura possui um formato semicircular e um diâmetro dorsoventral de 21,2 $\mathrm{mm}$ e anteroposterior em torno de $18,6 \mathrm{~mm}$.

UFES-Pal-001b representa parte do corpo mandibular do dentário esquerdo (Figuras 4A-B). Possui 7,1 cm de largura, aproximadamente $18 \mathrm{~cm}$ de comprimento e $15,6 \mathrm{~cm}$ de altura. Sua face vestibular é levemente côncava. Os quatro primeiros dentes molariformes (m1-m4) estão presentes em seus respectivos alvéolos. Destes, o $\mathrm{m} 1$ e o $\mathrm{m} 2$ estão fragmentados transversalmente, o $\mathrm{m} 4$ está fragmentado longitudinalmente, e apenas o $\mathrm{m} 3$ encontra-se bem preservado. $\mathrm{O} \mathrm{m} 1$ apresenta apenas a porção interalveolar preservada, a qual pode ser observada em vista anterior. Seu alvéolo encontra-se 

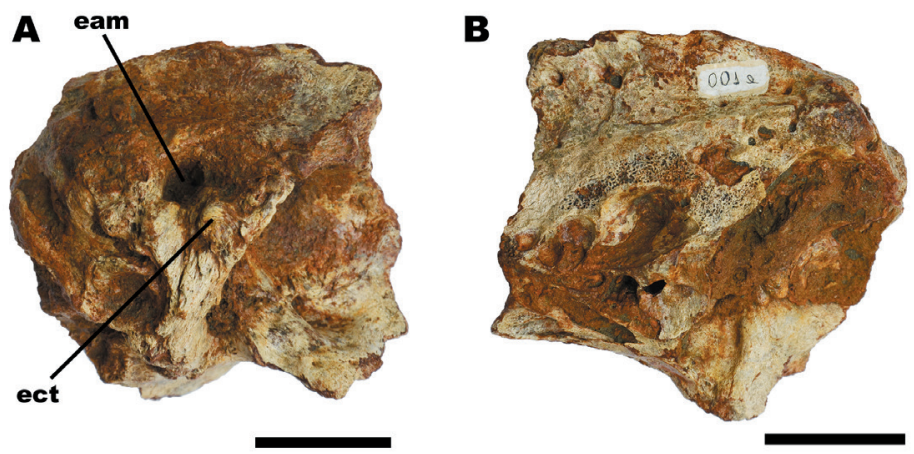

Figura 3. Fragmento da região posterior do crânio de Eremotherium laurillardi da localidade Alto Moledo (UFES-Pal-001e). A, vista lateral esquerda; B, vista medial. Abreviações: eam, abertura do meato acústico externo; ect, ectotimpânico. Escalas $=5 \mathrm{~cm}$.

Figure 3. Fragment of the posterior part of the skull of Eremotherium laurillardi from the locality of Alto Moledo (UFES-Pal-001e). A, left lateral view; B, medial view. Abbreviations: eam, opening of the external acoustic meatus; ect, ectotympanic. Scale bars $=5 \mathrm{~cm}$.

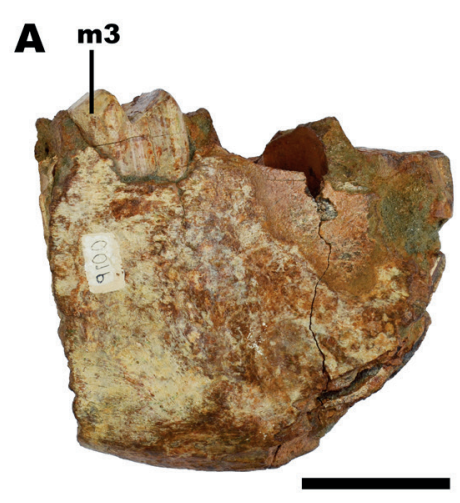

C
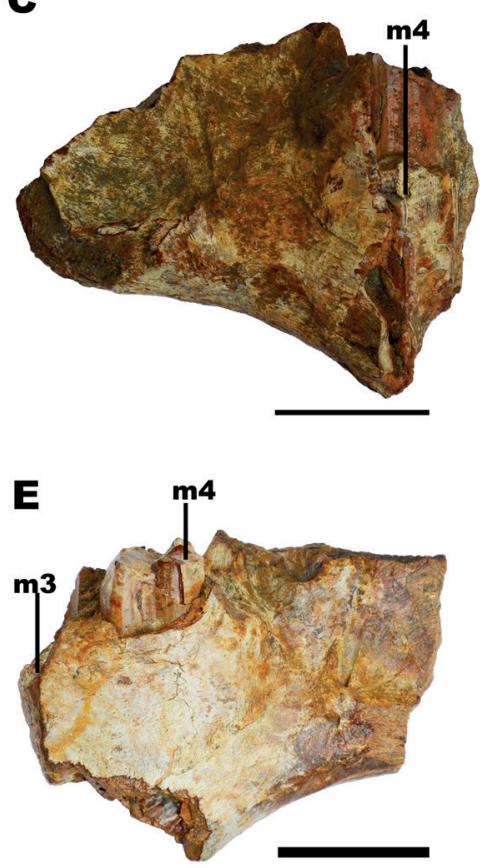

B

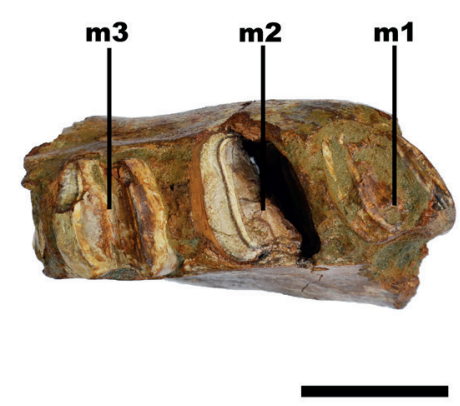

D

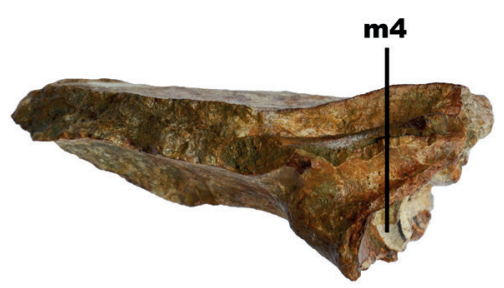

$\mathbf{F}$

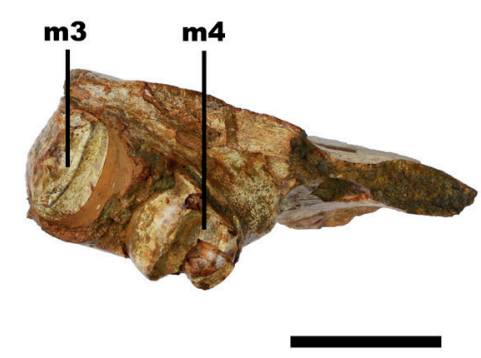

Figura 4.A-B, fragmento de dentário esquerdo de Eremotherium laurillardi da localidade Alto Moledo (UFES-Pal-001b). A, vista medial; B, vista oclusal. C-D, fragmento de dentário esquerdo de E. laurillardi da localidade Alto Moledo (UFES-Pal-001g). C, vista medial; D, vista oclusal. E-F, fragmento de dentário direito de E. laurillardi da localidade Alto Moledo (UFES-Pal-001a). E, vista medial; F, vista oclusal. Abreviações: $\mathbf{m}$, molariforme inferior. Escalas $=5 \mathrm{~cm}$.

Figure 4. A-B, fragment of the left dentary of Eremotherium laurillardi from the locality of Alto Moledo (UFES-Pal-001b). A, medial view; B, occlusal view. C-D, fragment of the left dentary of E. laurillardi from the locality of Alto Moledo (Ufes-Pal-001g). C, medial view; D, occlusal view. E-F, fragment of the right dentary of E. laurillardi from the locality of Alto Moledo (UFES-Pal-001a). E, medial view; F, occlusal view. Abbreviations: m, lower molariform. Scale bars: $=5 \mathrm{~cm}$. 
preenchido por sedimento arenoso de cor cinza. $\mathrm{O} \mathrm{m} 2$, por sua vez, apresenta apenas parte da porção interalveolar. O m3 apresenta a superfície oclusal com duas cristas, uma mesial e outra distal, que são separadas por um sulco profundo.

A porção UFES-Pal-001g conecta-se com a hemimandíbula UFES-Pal-001b e representa a região posterior do corpo mandibular e a parte mais anterior do ramo mandibular esquerdo (Figuras 4C-D). Possui $16 \mathrm{~cm}$ de comprimento e 13,1 $\mathrm{cm}$ de altura e possui uma concavidade na região ventral, bem como lateralmente. Parte da porção interalveolar do m4 está presente, inserida no alvéolo. A porção preservada do dentário direito (UFES-Pal-001a; Figuras 4E-F) tem 14,9 cm de altura e 18,2 cm de comprimento e contém parte do ramo e do corpo mandibular. Sua superfície ventral é côncava, similarmente à descrita em UFES-Pal-001g. Esta porção inclui o terceiro (m3) e quarto (m4) dentes molariformes encaixados em seus respectivos alvéolos. Apenas parte da porção interalveolar do $\mathrm{m} 3$ encontra-se preservada. A superfície oclusal do $\mathrm{m} 4$ é observada e possui apenas uma crista preservada; o ramo mandibular dificulta sua visualização em vista lateral.
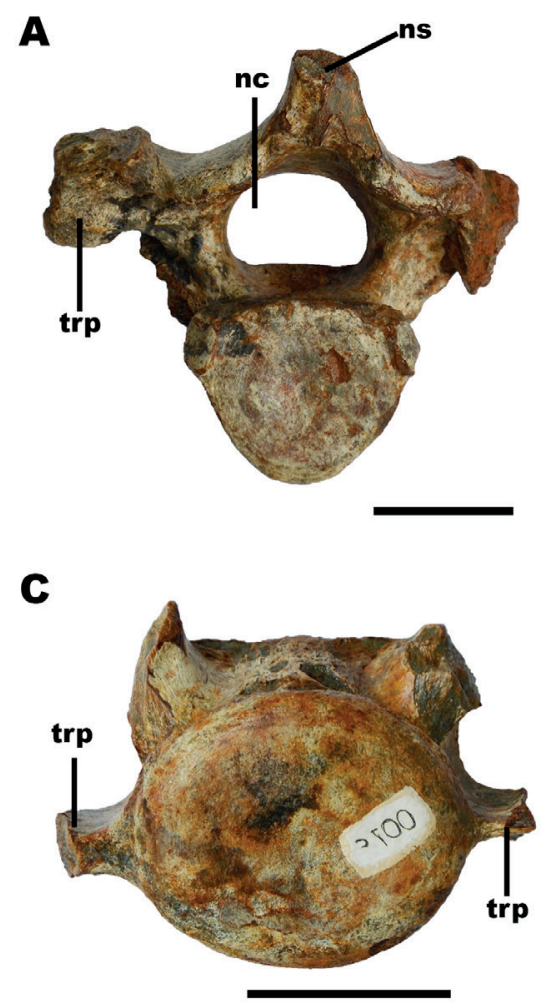

A vértebra torácica UFES-Pal-001d (Figuras 5A-B) mede aproximadamente $16,3 \mathrm{~cm}$ de altura, $21,8 \mathrm{~cm}$ de largura e aproximadamente $19 \mathrm{~cm}$ de comprimento (as medidas incluem o espinho neural). O centro vertebral possui formato cilíndrico e as faces articulares têm formato semitriangular, o que a difere de vértebras cervicais e lombares, nas quais elas são ovais arredondadas (Cartelle, 1992). O canal neural é oval e possui um diâmetro menor do que o do corpo vertebral. As parapófises e diapófises são posicionadas lateralmente e separadas por um pequeno sulco. A diapófise é localizada mais dorsalmente e direcionada lateralmente, enquanto as parapófises são direcionadas lateroventralmente. $\mathrm{O}$ espinho neural é direcionado dorsocaudalmente. Todas as zigapófises estão preservadas e são planas e ovais. As prézigapófises localizam-se na borda anterior do arco neural e possuem orientação dorsal. As pós-zigapófises encontramse na parte inferior da borda posterior do arco neural, são separadas pelo espinho neural e possuem uma orientação ventral. $O$ espécime UFES-Pal-001c representa o centro vertebral de uma vértebra cervical (Figura 5C). Difere da
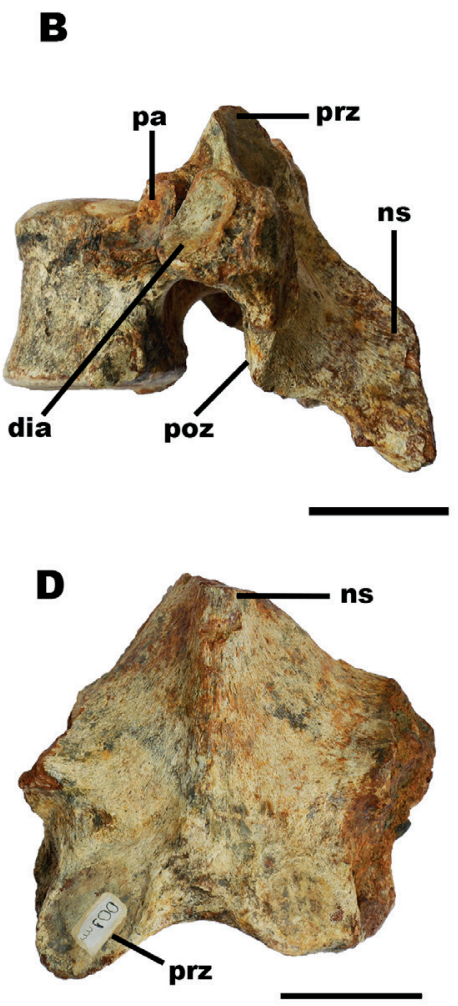

Figura 5. A-B, vértebra torácica de Eremotherium laurillardi da localidade Alto Moledo (UFES-Pal-001d). A, vista caudal; B, vista lateral esquerda. C, corpo vertebral de E. laurillardi da localidade Alto Moledo (UFES-Pal-001c) em vista caudal. D, arco neural de E. laurillardi da localidade Alto Moledo (UFES-Pal-001m) em vista dorsal. Abreviações: dia, diapófise; nc, canal neural; ns, espinho neural; pa, parapófise; poz, pós-zigapófise; prz, pré-zigapófise; trp, processo transverso. Escalas $=5 \mathrm{~cm}$.

Figure 5. A-B, thoracic vertebra of Eremotherium laurillardi from the locality of Alto Moledo (UFES-Pal-001d). A, caudal view; B, left lateral view. C, vertebral centrum of E. laurillardi from the locality of Alto Moledo (UFES-Pal-001c) in caudal view. D, neural arch of E. laurillardi from the locality of Alto Moledo (UFES-Pal-001m) in dorsal view. Abbreviations: dia, diapophysis; nc, neural canal; ns, neural spine; pa, parapophysis; poz, post-zygapophysis; prz, pre-zygapophysis; trp, transverse process. Scale bars $=5 \mathrm{~cm}$. 
vértebra torácica UFES-Pal-001d em tamanho e forma, sendo sua superfície articular anterior menor e de formato arredondado, com $6,4 \mathrm{~cm}$ de comprimento e o mesmo de altura. Esta estrutura possui preservadas apenas as partes proximais de seus processos transversos. O exemplar UFESPal- $001 \mathrm{~m}$ consiste em um arco neural isolado com 14,7 $\mathrm{cm}$ de comprimento e aproximadamente $15 \mathrm{~cm}$ de largura (Figura 5D). As pré-zigapófises são bem desenvolvidas, com formato oval, e localizadas em sua margem anterior. Pela forma e dimensões, este fragmento pertence a uma vértebra torácica.

A tíbia esquerda, UFES-Pal-001n (Figuras 6A-D), é representada por um fragmento incluindo sua epífise distal, o qual tem aproximadamente $27 \mathrm{~cm}$ de comprimento e $21 \mathrm{~cm}$ de largura. Sua superfície articular possui duas concavidades bem desenvolvidas, uma lateral e outra medial, que são separadas por uma ligeira elevação orientada anteroposteriormente. Enquanto a concavidade lateral é menor e quase hemisférica, a medial é ao menos duas vezes maior do que a lateral e apresenta um formato de meia-lua. Embora a tíbia e a fíbula possam vir a fusionarem-se em suas extremidades proximais ou, em alguns casos, em ambas as extremidades (Cartelle, 1992), a fíbula não se encontra fusionada a este elemento. Porém, na face cranial da concavidade medial, é possível observar um grande sulco oblíquo com orientação laterodistal, que servia de inserção ao ligamento da articulação fibrosa entre estes ossos (Cartelle, 1992). Ainda nesta face, é possível observar um pequeno sulco oblíquo, direcionado mais medialmente, e que era destinado à fixação de tendões (Cartelle, 1992).

Ordem NOTOUNGULATA Roth, 1903

Subordem TOXODONTIA Owen, 1853

Família TOXODONTIDAE Owen, 1845

Subfamília TOXODONTINAE Trouessart, 1898

(Figuras 7A-C)
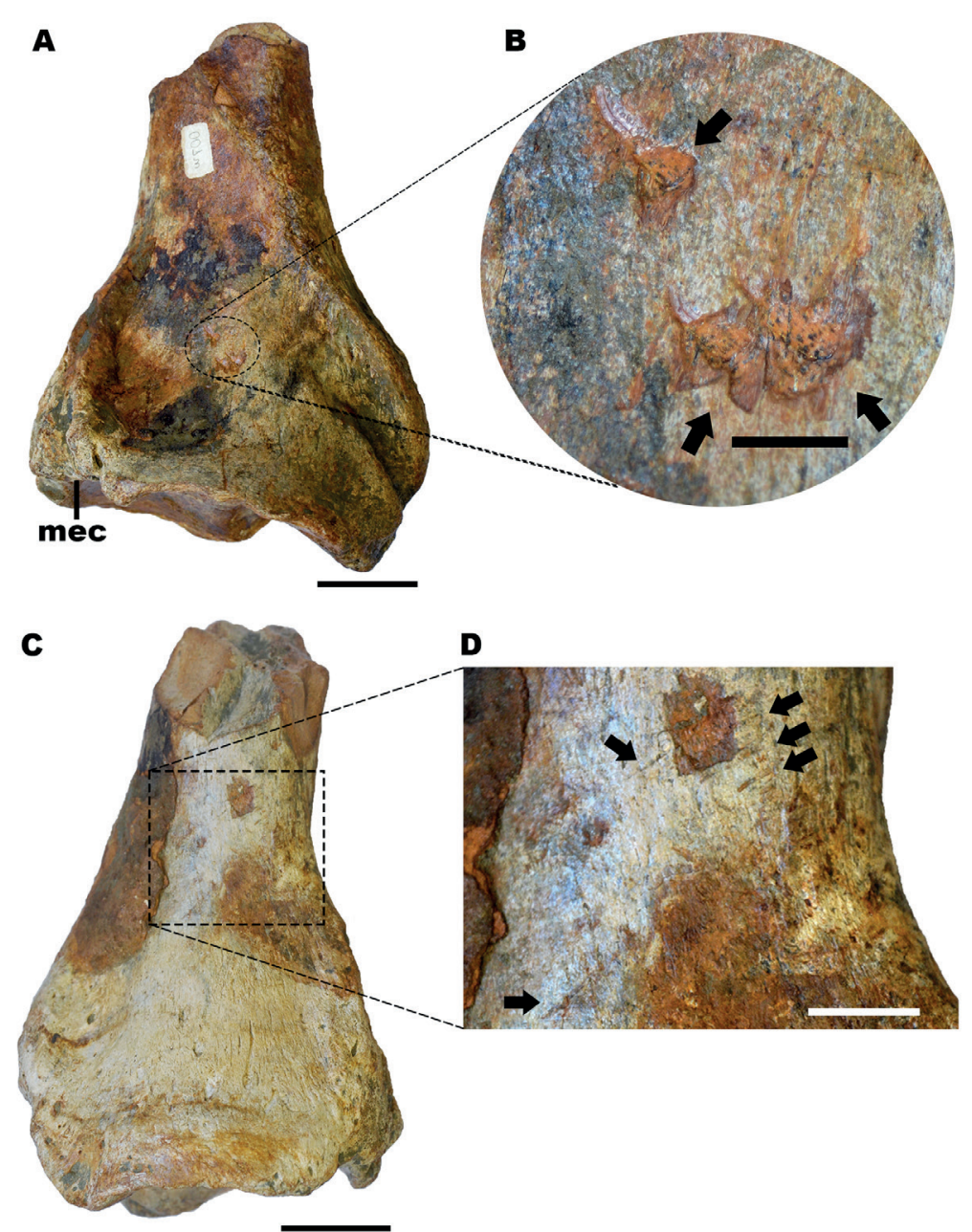

Figura 6. Porção distal da tíbia esquerda de Eremotherium laurillardi da localidade Alto Moledo (UFES-Pal-001n). A, vista anterior; B, detalhe de A. C, vista posterior. D, detalhe de C. Abreviação: mec, concavidade média. Setas indicam marcas de Praedichnia. Escalas: A, C = 5cm; B = $1 \mathrm{~cm} ; \mathrm{D}=2 \mathrm{~cm}$.

Figure 6. Distal portion of the left tibia of Eremotherium laurillardi from the locality of Alto Moledo (UFES-Pal-001n). A, anterior view. B, detail of A. C, posterior view. D, detail of C. Abbreviation: mec, medial concavity. Arrows indicate Praedichnia marks. Scale bars: $A, C=5 \mathrm{~cm} ; \mathrm{B}=1 \mathrm{~cm} ; \mathrm{D}=2 \mathrm{~cm}$. 
O espécime UFES-Pal-0011 consiste em um fragmento de dente, o qual possui esmalte em apenas uma de suas faces sendo compatível com um fragmento do quarto pré-molar de um Toxodontinae (Dantas \& Zucon, 2007; Nascimento, 2008) (Figuras 7A-C). Esta face preservada, a vestibular, é côncava. Em vista oclusal o espécime apresenta 15,5 mm de comprimento mesiodistal. Em vista vestibular, sua altura preservada é de aproximadamente $28,5 \mathrm{~mm}$. Caso confirmado, este é o primeiro registro de Toxodontidae para o Estado do Espírito Santo.

Ordem PROBOSCIDEA Illiger, 1811 Família GOMPHOTHERIIDAE Hay, 1922

Notiomastodon Cabrera, 1929

Notiomastodon cf. N. platensis

(Ameghino, 1888)

(Figuras 7D-E)
O fêmur direito (UFES-Pal-001h) está fragmentado e é representado por sua porção distal, incluindo apenas o epicôndilo medial (Figuras 7D-E). O epicôndilo lateral foi perdido. O espécime apresenta $14,8 \mathrm{~cm}$ de comprimento, 12,0 $\mathrm{cm}$ de largura na epífise distal e $5,8 \mathrm{~cm}$ de diâmetro na parte preservada da diáfise. Seu epicôndilo medial possui $6,4 \mathrm{~cm}$ de comprimento e 3,8 cm de largura. Lateralmente ao epicôndilo é possível observar a fossa intercondilar. A epífise distal se encontra fusionada, indicando tratar-se de um indivíduo adulto.

Gonfotérios já foram descritos para o Estado do Espírito Santo por Paula Couto (1978), com base em um molar e em um astrágalo muito fragmentado atribuídos à espécie Haplomastodon waringi. No entanto, recentemente Mothé et al. (2012) demonstraram que todos os gonfotérios de planície da América do Sul pertencem a uma única espécie, Notiomastodon platensis.

Classe MAMMALIA Linnaeus, 1758 indeterminados (Figuras 8A-F)
A

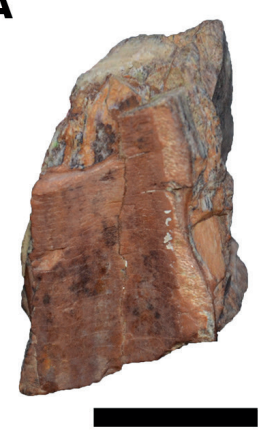

B

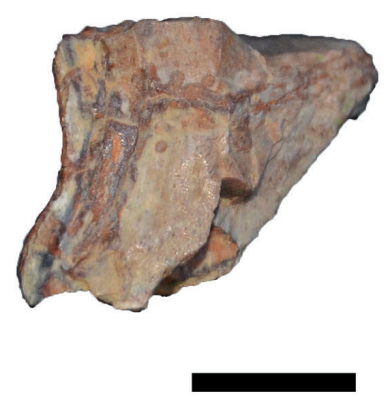

C

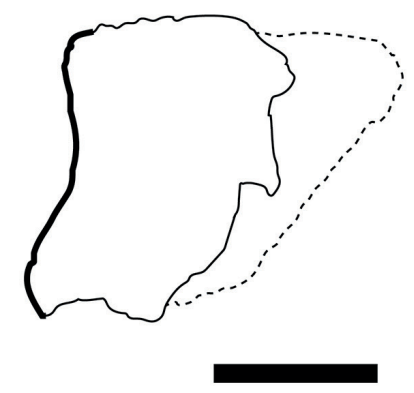

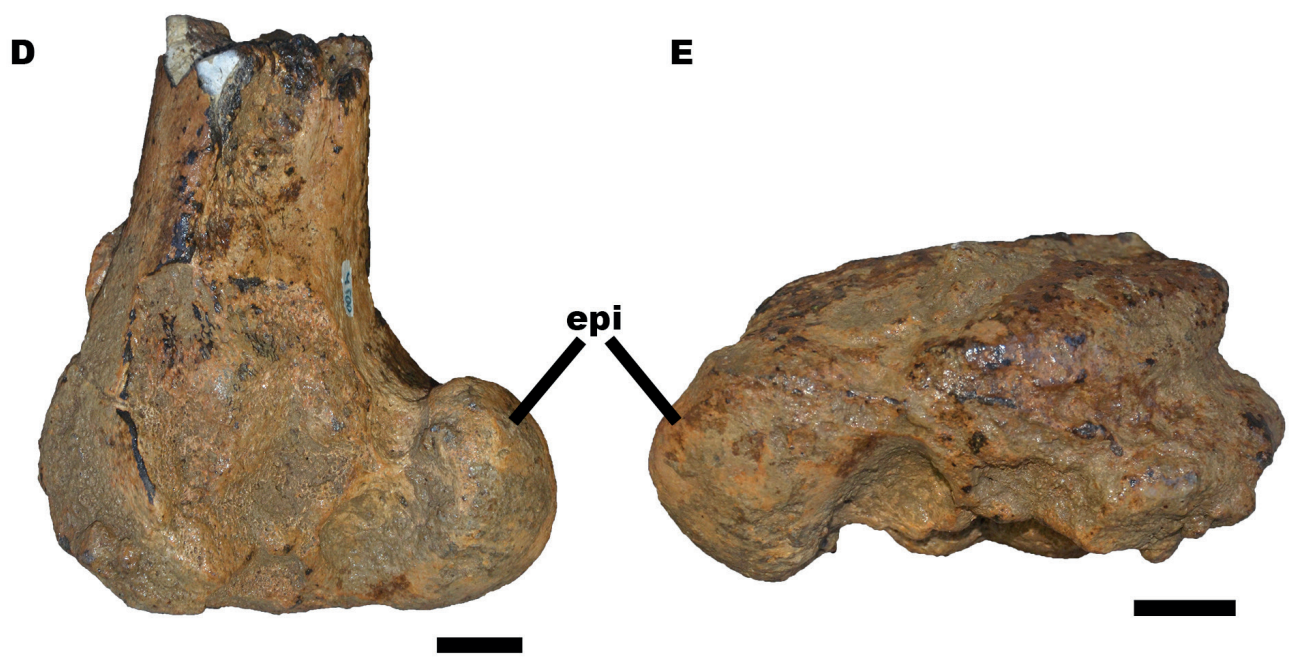

Figura 7. A-C, fragmento de um dente de Toxodontinae da localidade Alto Moledo (UFES-Pal-0011). A, vista vestibular; B, vista oclusal; C, desenho esquemático de B; linha em negrito indica o esmalte. D-E, porção distal do fêmur direito de Notiomastodon cf. N. platensis (UFES-Pal-001h). D, vista caudal; E, vista distal. Abreviações: epi, epicôndilo. Escalas: A-C $=1 \mathrm{~cm} ; \mathrm{D}-\mathrm{E}=2 \mathrm{~cm}$.

Figure 7. A-C, Tooth fragment of a Toxodontinae from the locality of Alto Moledo (UFES-Pal-0011). A, vestibular view; B, occlusal view; C, scheme of B; bold line indicates the enamel. D-E, distal portion of the right femur of Notiomastodon cf. N. platensis (UFES-Pal-001h). D, caudal view; E, distal view. Abbreviations: epi, epicondyle. Scale bars: $\mathrm{A}-\mathrm{C}=1 \mathrm{~cm} ; \mathrm{D}-\mathrm{E}=2 \mathrm{~cm}$. 
Há alguns fragmentos esqueléticos que podem ser identificados como pertencentes a mamíferos de grande porte e cuja anatomia é compatível com a de Eremotherium laurillardi, embora estejam muito incompletos para permitir uma identificação mais precisa. Dentre os três fragmentos de costelas presentes, apenas um possui preservado o tubérculo, UFES-Pal-001i (Figura 8C). Ele possui aproximadamente 25 $\mathrm{cm}$ de comprimento, $5,2 \mathrm{~cm}$ de altura na porção mais proximal e $4,4 \mathrm{~cm}$ na sua porção distal preservada. Ventralmente, apresenta uma curvatura que, em conjunto com as outras costelas, formava uma feição cônica (Cartelle, 1992). Essa costela também apresenta um nítido sulco longitudinal. As outras costelas (UFES-Pal-001j; UFES-Pal-001p) são representadas apenas por parte de seu corpo; porém, suas

A

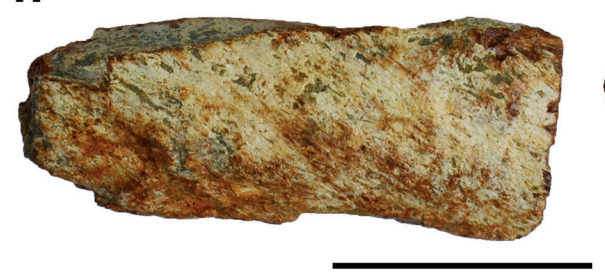

B

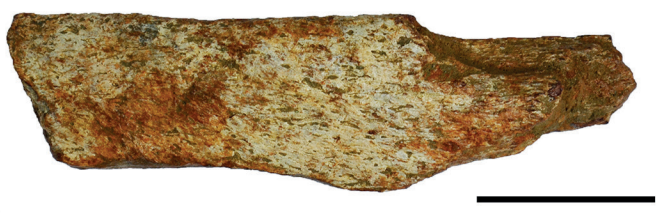

C

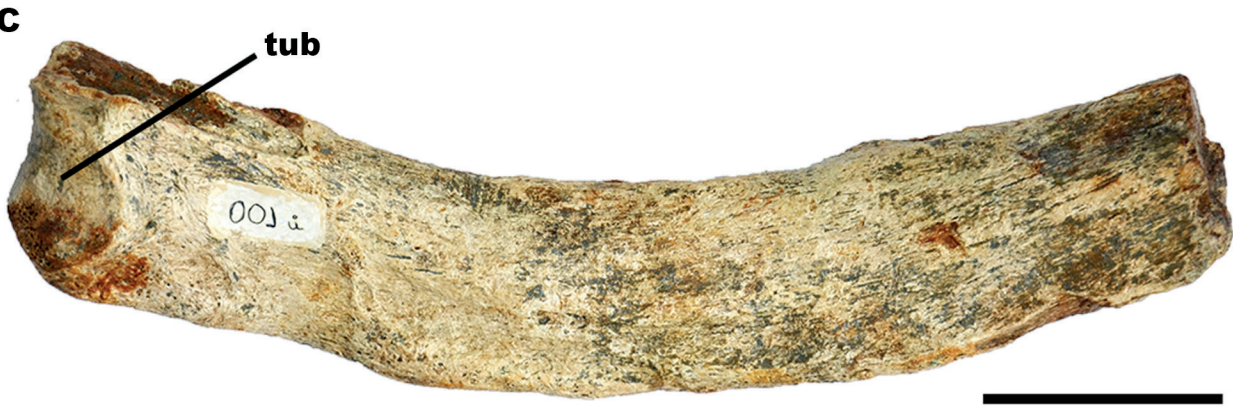

D

$\mathbf{E}$
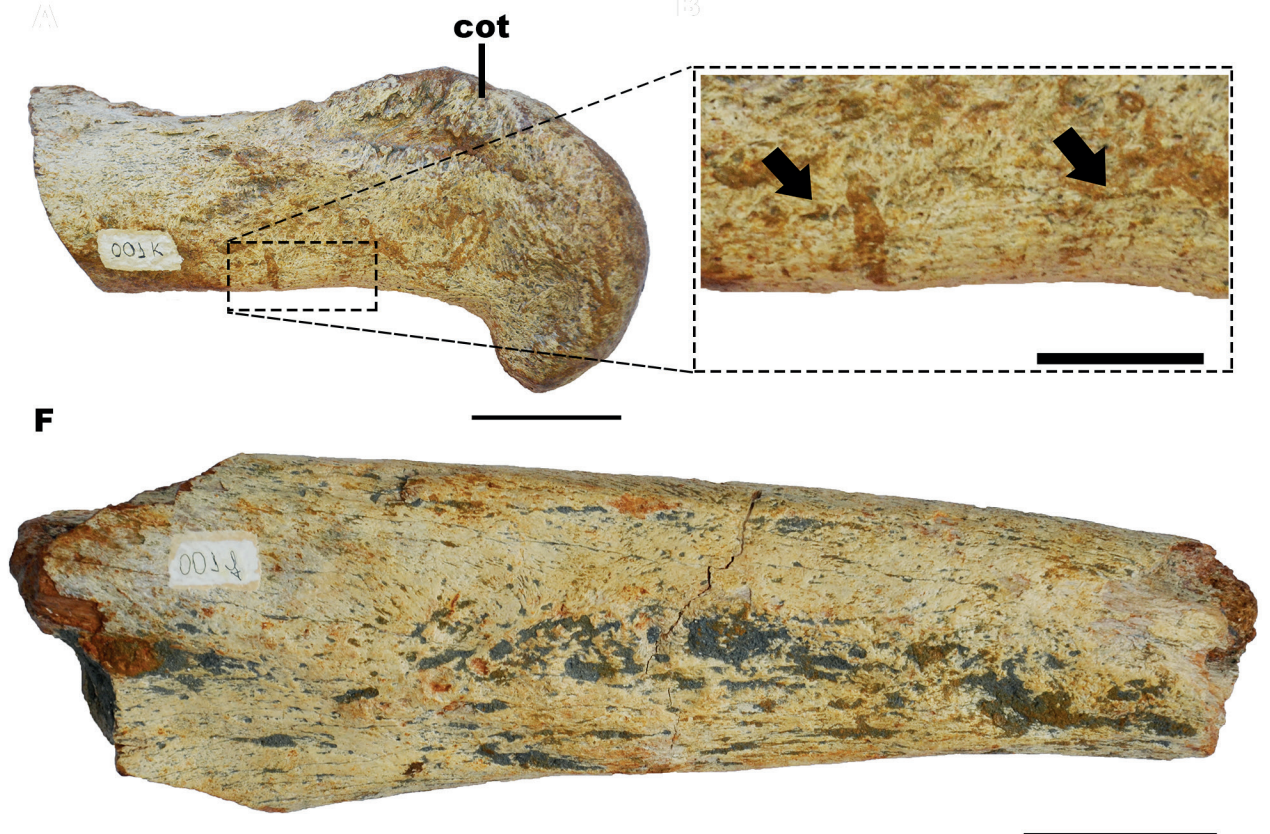

Figura 8. A-C, fragmentos de costelas de mamíferos de grande porte da localidade Alto Moledo. A, UFES-Pal-001j; B, UFES-Pal-001p; C, UFES-Pal-001i. D-E, clavícula esquerda de um mamífero de grande porte da localidade Alto Moledo (UFES-Pal-001k). D, espécime em vista dorsal; E, detalhe de D. F, possível ulna de um mamífero de grande porte da localidade Alto Moledo (UFES-Pal-001f). Abreviações: cot, tubérculo coronoide; tub, tubérculo. Setas indicam marcas de dessecação. Escalas: A-D, $F=5 \mathrm{~cm} ; \mathrm{E}=2 \mathrm{~cm}$.

Figure 8. A-C, Rib fragments of a large-bodied mammalfrom the locality of Alto Moledo. A, UFES-Pal-001j; B, UFES-Pal-001p; C, UFES-Pal-001i. D-E, left clavicle of a large-bodied mammal from the locality of Alto Moledo (UFES-Pal-001k). D, specimen in dorsal view; E, detail of D. F, possible ulna of a large-bodied mammal from the locality of Alto Moledo (UFES-Pal-001f). Abbreviations: cot, coronoid tubercle; tub, turbercle. Arrows point to desiccation marks. Scale bars: A-D, $F=5 \mathrm{~cm} ; \mathrm{E}=2 \mathrm{~cm}$. 
curvaturas e sulcos longitudinais são facilmente reconhecíveis (Figura 8A-B). O exemplar UFES-Pal-001k representa a porção acromial de uma clavícula esquerda (Figura 8D), medindo aproximadamente $23,5 \mathrm{~cm}$ de comprimento e 10,4 $\mathrm{cm}$ de altura. Seu tubérculo coronoide é grande e robusto, e está visível próximo à extremidade acromial. UFES-Pal-001f é parte da diáfise de um osso longo, possivelmente uma ulna (Figura 8F). Este exemplar apresenta aproximadamente 34 $\mathrm{cm}$ de comprimento e $4,7 \mathrm{~cm}$ de largura. Possui um formato levemente achatado, resultando em uma seção transversal bastante ovalada.

\section{CARACTERIZAÇÃO TAFONÔMICA}

Considerando-se os espécimes identificados como Eremotherium laurillardi e como Mammalia indeterminados, o NISP corresponde a treze. O MNI levou em consideração a simetria, tamanho e estágio ontogenético dos mesmos (Badgley, 1986; Lyman, 1994) e é consistente com a presença de apenas um indivíduo de E. laurillardi. O FTI dos espécimes foi estimado segundo Araújo-Júnior et al. (2012), porém notase que nem todos os espécimes encontram-se preservados inteiros e, portanto, estes dados são aproximados (Tabela 1).

Com relação à integridade física dos espécimes (Tabela 2), com a exceção de UFES-Pal-001d (vértebra torácica) e UFESPal-001i (costela), que se apresentam parcialmente completos, todos os outros foram preservados como fragmentos (sensu Behrensmeyer, 1991). Em UFES-Pal-001d, o processo transverso esquerdo e a porção apical do seu espinho neural estão ausentes (Figura 5A). Nos fragmentos das outras vértebras, nenhum dos processos está presente e apenas algumas das articulações estão presentes: em UFES-Pal$001 \mathrm{c}$ os processos estão ausentes, e em UFES-Pal-001m as pós-zigapófises encontram-se ausentes e o espinho neural apresenta apenas sua base, incluindo as pré-zigapófises (Figura 5C-D). Em UFES-Pal-001i apenas o capítulo na extremidade dorsal, a parte distal da sua diapófise e sua extremidade ventral estão ausentes (Figura 8C).

As marcas de dessecação observadas no material são caracterizadas pela presença de fissuras paralelas às fibras ósseas, condizentes com o estágio 1 de intemperismo (sensu Behrensmeyer, 1978) (Figura 8E). A abrasão presente no material atinge níveis moderados, sendo classificada como estágio 1 (sensu Shipman, 1981), pelas bordas e fraturas presentes nos espécimes exibirem superfícies arredondadas. Quanto aos estágios de incrustação, todos os espécimes são concordantes como estágio 0 (sensu Maldonado et al., 2016).

Na superfície cortical da tíbia são observadas marcas que diferem das cicatrizes musculares e do padrão esperado para as marcas de dessecação causadas pelo intemperismo. Estas marcas se apresentam como ranhuras exibindo um formato de "U" na seção transversal, afetam somente o osso cortical e suas superfícies são estriadas longitudinalmente. Dois tipos diferentes estão presentes. Um deles consiste em cinco sulcos horizontais, orientados perpendicularmente às bordas do osso, localizados na porção da diáfise e variando entre 1 e $2 \mathrm{~cm}$ de comprimento e $0,1 \mathrm{~cm}$ de largura (Figura 6D). O segundo consiste em três marcas dispostas diagonalmente às bordas do osso, presentes na epífise, e que possuem em torno de 0,7 $\mathrm{cm}$ de comprimento e $0,1 \mathrm{~cm}$ da largura ao longo da ranhura; contudo, em uma das bordas um formato oval é observado medindo em torno de 0,4 $\mathrm{cm}$ de largura (Figura 6B).

\section{DISCUSSÃO}

Com a exceção do fragmento de dente, atribuído a Toxodontinae, e da porção de fêmur, pertencente a Notiomastodon, todos os demais espécimes aqui descritos são compatíveis com um indivíduo porque eles não apresentam ossos homólogos em duplicidade e possuem comprimentos proporcionais uns em relação aos outros, resultando em um MNI de um. Além disso, foram encontrados na mesma fenda. Os três espécimes de hemi-mandíbulas apontados na Tabela 1 são porções que não se sobrepõem e podem ser identificados como pertencentes à família Megatheriidae e à subfamília Megatheriinae por possuirem dentes molariformes muito alongados, prismáticos, quadrangulares, com duas cristas transversais e dispostos em uma série contínua, e pela presença de quatro molariformes inferiores (Paula Couto, 1979). O espécime de crânio pode ser identificado como Eremotherium devido ao seu ectotimpânico muito robusto, rugoso e com um alargamento triangular, e distinto de Megatherium, no qual este osso é menos rugoso e possui uma forma mais quadrangular (De Iuliis \& Cartelle, 1999). Além disso, a morfologia da mandíbula, dos molariformes, das vértebras e da tíbia é compatível com aquela descrita por Cartelle (1992) e Paula Couto (1978) para E. laurillardi, uma espécie cuja distribuição paleobiogeográfica estende-se por toda a Região Intertropical Brasileira (Cartelle \& De Iuliis, 1995). A diáfise e epífise da tíbia e as superfícies articulares das vértebras torácica e cervical apresentam-se completamente fusionadas, indicando maturidade osteológica (Dantas \& Zucon, 2007). Espécimes como as costelas, clavícula e a possível ulna não possuem características diagnósticas, mas possuem morfologia concordante com a de E. laurillardi.

Hipotetizamos que este indivíduo de Eremotherium laurillardi (como sugerido pelo MNI) tenha morrido externamente à fenda e tenha sido posteriormente transportado. De acordo com as marcas de dessecação, sugerimos que houve um tempo curto de exposição subaérea dos ossos após a morte do animal (Behrensmeyer, 1978). As marcas de dessecação são congruentes com uma exposição em ambiente mais aberto, pois na fenda os elementos esqueléticos estariam mais protegidos da ação direta das intempéries. Por fim, as diferenças entre o tamanho da abertura da fenda e as dimensões conhecidas para um indivíduo adulto de $E$. laurillardi demonstram que o animal dificilmente teria caído em vida na mesma.

Apesar de não ser possível acessar todo o material que foi originalmente resgatado, os valores de Transportabilidade Fluvial (FTI) observados demonstram uma homogeneidade entre fósseis mais e menos transportáveis, sendo observados espécimes representativos de elementos com FTI igual ou superior a 75, entre 75 e 50, e inferior a 50. O FTI indica, 
ainda, que estes fósseis possivelmente são representativos de uma assembleia periférica (sensu Araújo-Júnior, 2016), o que está de acordo com a hipótese de que o material provavelmente foi submetido a um transporte de curta distância (AraújoJúnior et al., 2012; Araújo-Júnior, 2016). Por fim, a presença de espécimes pertencentes a outros táxons (Toxodontinae e Notiomastodon) também corrobora a hipótese de transporte.

A significativa quantidade de fragmentos caracterizados pela presença de epífises ou diáfises de ossos longos e remoção de processos vertebrais pode ser relacionada a transporte hidráulico, embora aparentemente de baixa energia, pois essas regiões ósseas, as quais apresentam o córtex mais fino, são mais susceptíveis à quebra por choques mecânicos (Haynes, 1980; Buchmann et al., 2017). Além disso, deve-se considerar que, no momento do transporte, provavelmente estas estruturas estariam mais enfraquecidas pela exposição ao intemperismo (Behrensmeyer, 1978). A abrasão em níveis moderados também corrobora a hipótese de transporte hidráulico de curta distância por um fluxo de baixa energia (Shipman, 1981). Outro fator a ser apreciado é que o substrato presente externamente à fenda onde os fósseis foram recuperados era constituído principalmente por areia grossa (Souza Cunha et al., 1983), o que pode ter acarretado a abrasão moderada presente no material, mesmo com um transporte de curta distância (sensu Shipman, 1981). Apesar desta fenda se encontrar em um local mais baixo em relação ao relevo adjacente, nós sugerimos que a deposição ocorreu em consequência da drenagem retangular característica do local (Salviano da Costa, 1991), ocasionada por um fluxo hidráulico de alguma corrente tributária que desaguou na fenda antes da chegada na corrente principal. A condição parcialmente nivelada do local em relação ao cume da depressão é concordante com um fluxo hidráulico de energia baixa.

De acordo com a irregularidade da distribuição de marcas de dessecação na superfície dos fósseis, infere-se que nem todos os elementos esqueléticos foram totalmente soterrados após a entrada na fenda, permitindo a ação prolongada de intemperismo. A coloração acinzentada exibida em algumas porções do osso cortical revela ainda alteração da coloração por influência de minerais na etapa fossildiagenética (AraújoJúnior \& Marinho, 2013; Maldonado et al., 2016).

Apesar da superfície cortical se apresentar bastante danificada em virtude da dessecação, ranhuras são observadas no fragmento preservado da tíbia (Figura 6). Utilizando a proposta de Haynes (1983), as estruturas foram categorizadas como arranhões. O formato de "U" na secção transversal, a presença de traços que são paralelos uns aos outros e a distribuição horizontal e diagonal dos arranhões observados sugerem que eles sejam icnofósseis de alimentação (Praedichnia) e que tenham sido realizados por necrofagia por Carnivora (Haynes, 1980, 1982; Dominato et al., 2011; Araújo-Júnior et al., 2011, 2017; Wisshak et al., 2019) (Figura 9). De acordo com o comprimento e profundidade rasa exibida pelos arranhões, sugerimos que os mesmos tenham sido realizados por canídeos, os quais arrastam os
Tabela 1. Dados quantitativos dos fósseis de Eremotherium laurillardi e de mamíferos de grande porte não identificados da localidade Alto Moledo. Abreviações: NISP, número de espécimes identificados por táxon; MNI, número mínimo de indivíduos; FTI, Índice de Transporte Fluvial dos elementos.

Table 1. Quantitative data of the fossils of Eremotherium laurillardi and of unidentified large-bodied mammal fossils from the locality of Alto Moledo. Abbreviations: NISP, number of identified specimens per taxon; MNI, minimum number of individuals; FTI, Fluvial Transport Index of the elements.

\begin{tabular}{lccc}
\hline Elemento anatômico & NISP & MNI & FTI \\
\hline Crânio & 1 & 1 & - \\
Hemi-mandíbula & 3 & 1 & 34,56 \\
Vértebra torácica & 2 & 1 & 76,43 \\
Vértebra cervical & 1 & 1 & 96,64 \\
Costela & 3 & 1 & 53,98 \\
Clavícula & 1 & 1 & - \\
Tíbia & 1 & 1 & 72,84 \\
Ulna (?) & 1 & 1 & - \\
\hline
\end{tabular}

Tabela 2. Análise da integridade física dos elementos fósseis de Eremotherium laurillardi e de mamíferos de grande porte não identificados da localidade Alto Moledo.

Table 2. Analysis of the physical integrity of elements of Eremotherium laurillardi and of unidentified large-bodied mammal fossils from the locality of Alto Moledo.

\begin{tabular}{|c|c|c|}
\hline Espécime & Elemento anatômico & Integridade Física \\
\hline UFES-Pal-001e & Crânio & $\begin{array}{c}\text { Fragmento } \\
(<50 \% \text { do elemento })\end{array}$ \\
\hline UFES-Pal-001a & Hemi-mandíbula direita & $\begin{array}{c}\text { Fragmento } \\
(<50 \% \text { do elemento })\end{array}$ \\
\hline UFES-Pal-001b & $\begin{array}{l}\text { Hemi-mandíbula } \\
\text { esquerda }\end{array}$ & $\begin{array}{c}\text { Fragmento } \\
(<50 \% \text { do elemento })\end{array}$ \\
\hline UFES-Pal-001g & $\begin{array}{l}\text { Hemi-mandíbula } \\
\text { esquerda }\end{array}$ & $\begin{array}{c}\text { Fragmento } \\
(<50 \% \text { do elemento })\end{array}$ \\
\hline UFES-Pal-001d & Vértebra torácica & $\begin{array}{l}\text { Parcialmente completo } \\
\text { (50\%-90\% do elemento) }\end{array}$ \\
\hline UFES-Pal-001c & Vértebra cervical & $\begin{array}{c}\text { Fragmento } \\
(<50 \% \text { do elemento })\end{array}$ \\
\hline $\begin{array}{l}\text { UFES-Pal- } \\
001 \mathrm{~m}\end{array}$ & Vértebra torácica & $\begin{array}{c}\text { Fragmento } \\
(<50 \% \text { do elemento })\end{array}$ \\
\hline UFES-Pal-001i & Costela & $\begin{array}{l}\text { Parcialmente completo } \\
\text { (50\%-90\% do elemento) }\end{array}$ \\
\hline UFES-Pal-001j & Costela & $\begin{array}{c}\text { Fragmento } \\
(<50 \% \text { do elemento })\end{array}$ \\
\hline UFES-Pal-001p & Costela & $\begin{array}{c}\text { Fragmento } \\
(<50 \% \text { do elemento })\end{array}$ \\
\hline UFES-Pal-001k & Clavícula esquerda & $\begin{array}{c}\text { Fragmento } \\
(<50 \% \text { do elemento })\end{array}$ \\
\hline UFES-Pal-001n & Tíbia esquerda & $\begin{array}{c}\text { Fragmento } \\
(<50 \% \text { do elemento })\end{array}$ \\
\hline UFES-Pal-001f & Ulna (?) & $\begin{array}{c}\text { Fragmento } \\
(<50 \% \text { do elemento })\end{array}$ \\
\hline
\end{tabular}




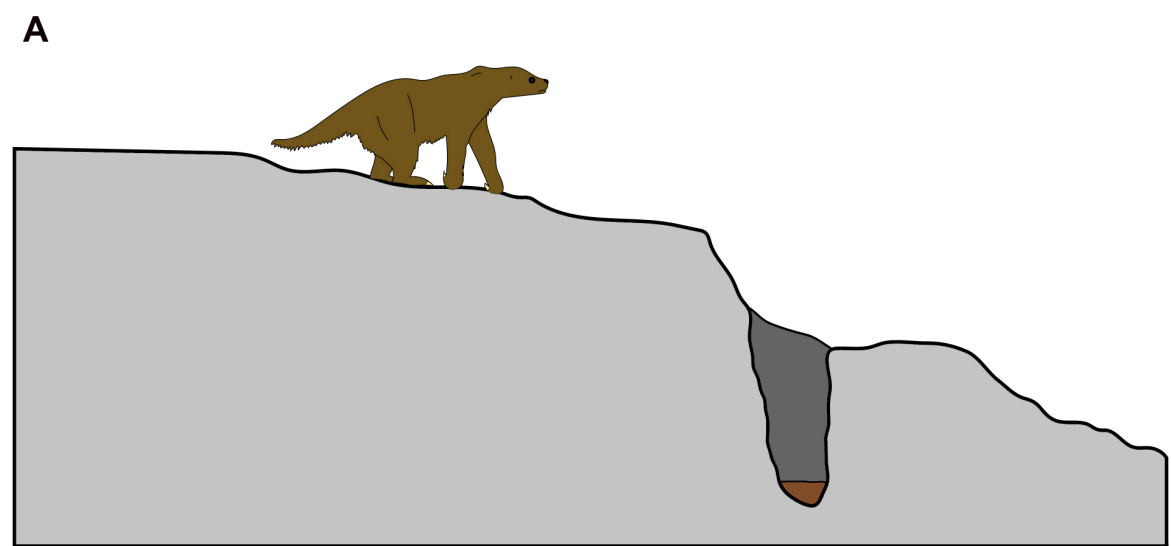

B

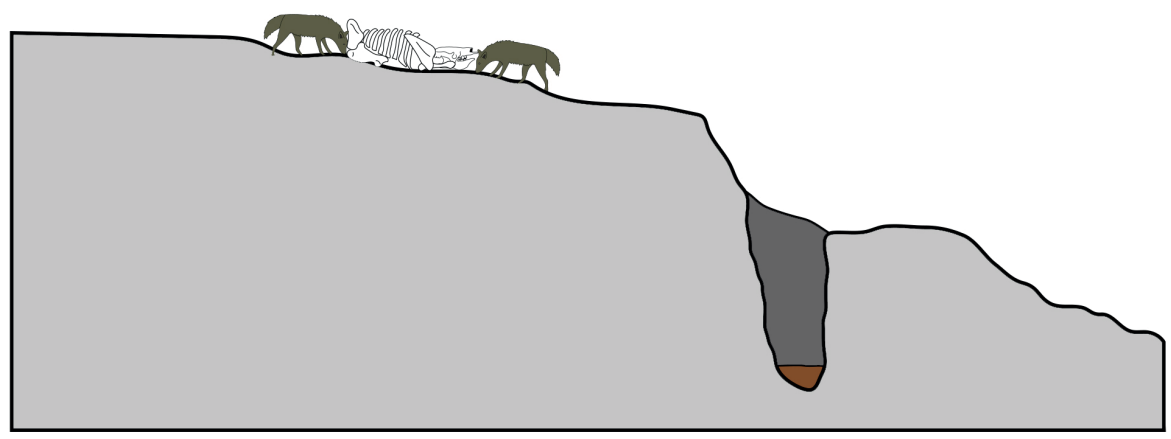

C

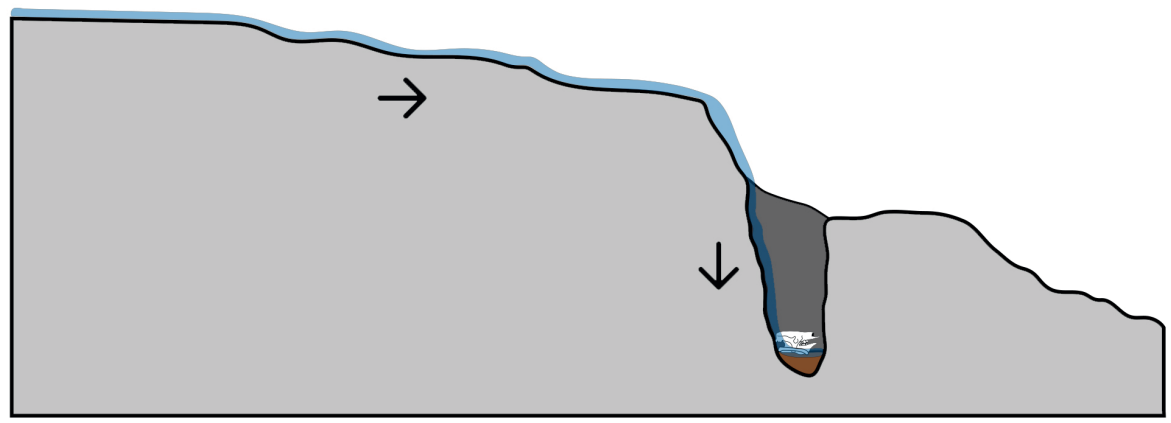

Figura 9. Desenho esquemático da formação do depósito da localidade Alto Moledo. A, representação de Eremotherium laurillardi em vida nas proximidades da fenda. B, representação de E. laurillardi após o óbito nas proximidades da fenda, com a carcaça sofrendo ação de canídeos necrófagos. C, representação do fluxo hidráulico de baixa energia carreando o indivíduo por uma distância curta, até sua deposição na fenda.

Figure 9. Schematic representation for the formation of the deposit from the locality of Alto Moledo. A, representation of a living Eremotherium laurillardi near the crevice. B, representation of E. laurillardi after death near the crevice, with its carcass suffering the action of canid scavengers. C, representation of the low energy hydraulic flow carrying the individual for a short distance until its deposition inside the crevice.

dentes produzindo marcas que danificam apenas a superfície cortical (Haynes, 1983; Araújo-Júnior et al., 2011). Apesar de arranhões como estes serem frequentemente descritos nas epífises e extremidades proximais das diáfises de ossos longos (Haynes, 1980, 1982; Dominato et al., 2011), eles também já foram observados na extremidade distal de uma tíbia pertencente a Smilodon populator (Araújo-Júnior et al.,
2017). O fato de felídeos comumente não deixarem marcas nas diáfises de ossos longos também apoia esta identificação (Haynes, 1983). O tamanho e localização dos arranhões descartam as hipóteses de predação, sendo interpretados como relacionados a eventos de necrofagia do osso concomitantes à necrólise do espécime (Araújo-Júnior et al., 2017), compatível com o hábito de roer epífises de ossos demonstrado por 
canídeos (Haynes, 1980, 1982, 1983). As diferenças no comprimento e largura dos arranhões observados podem estar relacionadas à forma e tamanho dos dentes dos necrófagos, bem como à intensidade da mordida (Dominato et al., 2011).

\section{CONCLUSÕES}

A hipótese para a formação deste depósito que mais se adequa às feições tafonômicas e paleoicnológicas apresentadas pelo material sugere a morte de um indivíduo de Eremotherium laurillardi ocorrida externamente, mas próxima à fenda. As assinaturas paleoicnológicas observadas aqui indicam que ocorreu o consumo da carcaça ou parte dela por canídeos necrófagos. As assinaturas tafonômicas indicam que, posteriormente, os ossos permaneceram expostos no ambiente por pouco espaço de tempo, até que, finalmente, um fluxo hidráulico de baixa energia carreou os espécimes ao interior de uma fenda formada por rochas metamórficas. Nesta fenda, o material permaneceu parcialmente soterrado por um sedimento argiloso e moderadamente protegido das intempéries, até seu resgate. Estes espécimes representam uma assembleia periférica (sensu Araújo-Júnior, 2016), as quais são normalmente associadas a depósitos em cavernas ou tanques, mas que também podem ser formadas em fendas localizadas em outros contextos sedimentares, embora com menor frequência. Assim, achados em frentes de mármore como estes, demonstram o potencial, ainda que baixo, de novas descobertas.

\section{AGRADECIMENTOS}

O presente trabalho foi realizado com apoio da Coordenação de Aperfeiçoamento de Pessoal de Nível Superior - Brasil (CAPES) - Código de Financiamento 001. Somos gratos às professoras R.M. Senna Melo e S.Z. Xavier (UFES) pelas informações sobre a coleta do material; a C. Cartelle e aos biólogos M.A.C. Veloso e L. Vilaboim Santos do Museu de Ciências Naturais da PUC Minas (Belo Horizonte, MG) pelo acesso à coleção e pelo apoio prestado durante a visita; a P.S. Bernarde (UFAC) pelo envio de bibliografia; a M.A.T. Dantas (UFBA) pelo auxílio nas identificações; a A. Gatti (UFES) e a R.G. Figueiredo (UFES) pelas correções de uma versão anterior deste trabalho; a E. Mayer (UNIFESSPA), a H. Araújo-Júnior (UERJ) e a um revisor anônimo pelas sugestões e correções do manuscrito; e aos editores A.M. Ribeiro (MCN/ SEMA) e K. Porpino (UERN) pelas correções.

\section{REFERÊNCIAS}

Albino, J.; Girardi, G. \& Nascimento, K.A. 2006. Espírito Santo. In: D. Muehe (org.) Erosão e progradação do litoral brasileiro, Ministério do Meio Ambiente, p. 229-264.

Araújo-Júnior, H.I. 2016. Classifying vertebrate assemblages preserved in Quaternary tank deposits: implications for vertebrate taphonomy and paleoecology. Palaeogeography, Palaeoclimatology, Palaeoecology, 445:147-152. doi:10.1016/j. palaeo.2015.12.025
Araújo-Júnior, H.I.; Barbosa, F.H.S. \& Silva, L.H.M. 2017. Overlapping paleoichnology, paleoecology and taphonomy: analysis of tooth traces in a Late Pleistocene-early Holocene megafaunal assemblage of Brazil and description of a new ichnotaxon in hard substrate. Palaeogeography, Palaeoclimatology, Palaeoecology, 468:122-128. doi:10.1016/j.palaeo.2016.12.007

Araújo-Júnior, H.I.; Bissaro-Júnior, M.C.; Santos, T.T.; Alves, R.S. \& Bergqvist, L.P. 2012. Tafonomia da megafauna pleistocênica brasileira: Fluvial Transport Index (FTI) em análises de representatividade óssea. Revista Brasileira de Paleontologia, 15:95-104. doi:10.4072/rbp.2012.1.08

Araújo-Júnior, H.I. \& Marinho, T.S. 2013. Taphonomy of a Baurusuchus (Crocodyliformes, Baurusuchidae) from the Adamantina Formation (Upper Cretaceous, Bauru Basin), Brazil: implications for preservational modes, time resolution and paleoecology. Journal of South American Earth Sciences, 47:90-99. doi:10.1016/j.jsames.2013.07.006

Araújo-Júnior, H.I.; Porpino, K.O. \& Bergqvist, L.P. 2011. Marcas de dentes de carnívoros/carniceiros em mamíferos pleistocênicos do Nordeste do Brasil. Revista Brasileira de Paleontologia, 14:291-296. doi:10.4072/rbp.2011.3.08

Araújo-Júnior, H.I.; Porpino, K.O.; Ximenes, C.L. \& Bergqvist, L.P. 2013. Unveiling the taphonomy of elusive natural tank deposits: a study case in the Pleistocene of northeastern Brazil. Palaeogeography, Palaeoclimatology, Palaeoecology, 378:5274. doi:10.1016/j.palaeo.2013.04.001

Badgley, C. 1986. Counting individuals in mammalian fossil assemblages from fluvial environments. Palaios, 1:328-338. doi: $10.2307 / 3514695$

Behrensmeyer, A.K. 1978. Taphonomic and ecologic information from bone weathering. Paleobiology, 4:150-162. doi:10.1017/ S0094837300005820

Behrensmeyer, A.K. 1991. Terrestrial vertebrate accumulations. In: P.A. Allison \& D.E.G. Briggs (eds.) Taphonomy: releasing the data lockedin the fossil record, Plenum Press, p. 291-335.

Bergqvist, L.P. \& Almeida, E.B. 2004. Biodiversidade de mamíferos fósseis brasileiros. Revista UnG. Geociências, 9:54-68.

Buchmann, R.; Silva-Guimarães, M.; Rocha-dos-Santos, B.C.A.; Pinheiro, R.S.; Rotti, A.; Ávilla, L.S.; Freitas, J. \& Araújo-Júnior, H.I. 2017. Mamíferos fósseis do Quaternário da Gruta Tacho de Ouro, Tocantins, norte do Brasil: Diversidade, tafonomia e aspectos paleoicnológicos e paleoambientais. Revista Brasileira de Paleontologia, 20:203-218. doi:10.4072/rbp.2017.2.05

Cartelle, C. 1992. Edentata e megamamíferos herbivoros extintos da Toca dos Ossos (Ourolândia, BA). Programa de Pós-Graduação em Morfologia, Universidade Federal de Minas Gerais, Tese de Doutorado, $301 \mathrm{p}$.

Cartelle, C. \& De Iuliis, G. 1995. Eremotherium laurillardi: the Panamerican late Pleistocene megatheriid sloth. Journal of Vertebrate Paleontology, 15:830-841. doi:10.1080/02724634 .1995 .10011265

Dantas, M.A.T. \& Zucon, M.H. 2007. Sobre a ocorrência de fósseis da megafauna do Pleistoceno Final em Coronel João Sá, Bahia, Brasil. Revista UnG. Geociências, 6:191-200.

De Iuliis, G. \& Cartelle, C. 1999. A new giant megatheriine ground sloth (Mammalia: Xenarthra: Megatheriidae) from the late Blancan to early Irvingtonian of Florida. Zoological Journal of the Linnean Society, 127:495-515. doi:10.1006/zjls. 1998.0190

De Paula, A. 2016. Preguiça gigante de Cachoeiro. A Tribuna, p. 18, 03 jan. 2016.

Dominato, V.H.S.; Mothé, D.; Costa-da-Silva, R. \& Avilla, L.S. 2011. Evidence of scavenging on remains of the gomphothere 
Haplomastodon waringi (Proboscidea: Mammalia) from the Pleistocene of Brazil: taphonomic and paleoecological remarks. Journal of South American Earth Sciences, 31:171-177. doi:10.1016/j.jsames.2011.01.002

Frison, G.C. \& Todd, L.C. 1986. The Colby mammoth site: taphonomy and archaeology of a Clovis Kill in Northern Wyoming. Albuquerque, University of New Mexico Press, 238 p.

Haynes, G. 1980. Evidence of carnivore gnawing on Pleistocene and recent mammalian bones. Paleobiology, 6:341-351. doi:10.1017/S0094837300006849

Haynes, G. 1982. Utilization and skeletal disturbances of North American prey carcasses. Artic, 35:266-281. doi:10.14430/ arctic 2325

Haynes, G. 1983. A guide for differentiating mammalian carnivore taxa responsible for gnaw damage to herbivore limb bones. Paleobiology, 9:164-172. doi:10.1017/S0094837300007545

Lyman, R.L. 1994. Vertebrate taphonomy. Cambridge, Cambridge University Press, 524 p. doi:10.1017/CBO9781139878302

Maldonado, V.; Monteiro, L.G.P.; Rotti, A.; Pereira, C.; AraújoJúnior, H.I. \& Avilla, L.S. 2016. Taphonomic aspects of deer (Mammalia, Cetartiodactyla, Cervidae) remains from a Quaternary cave deposit in Northern Brazil. Journal of Sedimentary Environments, 1:234-248. doi:10.12957/ jse.2016.23026

Mothé, D.; Avilla, L.S.; Cozzuol, M. \& Winck, G.R. 2012. Taxonomic revision of the Quaternary gomphotheres (Mammalia: Proboscidea: Gomphotheriidae) from the South American lowlands. Quaternary International, 276-277:2-7. doi:10.1016/j.quaint.2011.05.018

Nascimento, E.R. 2008. Os Xenarthra Pilosa (Megatheriidae), Notoungulata (Toxodontidae) e Proboscidea (Gomphotheriidae) da Formação Rio Madeira, Pleistoceno superior, Estado de
Rondônia, Brasil. Programa de Pós-Graduação em Geociências, Universidade Federal do Rio Grande do Sul, Dissertação de Mestrado, $113 \mathrm{p}$.

Paula Couto, C. 1978. Mamíferos fósseis do Pleistoceno do Espírito Santo. Anais da Academia Brasileira de Ciências, 50:365-379.

Paula Couto, C. 1979. Tratado de Paleomastozoologia. Rio de Janeiro, Academia Brasileira de Ciências, 590 p.

Salviano da Costa, I.L. 1991. Cachoeiro, suas pedras, sua história. Cachoeiro do Itapemirim, Sagraf Artes Gráficas Ltda., 242 p.

Shipman, P. 1981. Life history of a fossil: an introduction to taphonomy and paleoecology. Cambridge and London, Harvard University Press, 222 p.

Souza Cunha, F.L.; Xavier, S.Z. \& Melo, S.M.S. 1983. Novo registro de edentado fóssil na região calcária de Itaoca, Cachoeiro de Itapemirim, Espírito Santo. In: CONGRESSO BRASILEIRO DE ZOOLOGIA, 10, 1983. Resumos, Belo Horizonte, UFMG, p. $440-441$.

Vieira, V.S. \& Menezes, R.G. 2015. Geologia e recursos minerais do estado do Espírito Santo. Belo Horizonte, CPRM, 294 p.

Voorhies, M.R. 1969. Taphonomy and population dynamics of an Early Pliocene fauna, Knox County, Nebraska. Rocky Mountain Geology, 8:1-69. doi:10.2113/gsrocky.8.special_paper_1.1

Wisshak, M.; Knaust, D. \& Bertling, M. 2019. Bioerosion ichnotaxa: review and annotated list. Facies, 65:24. doi:10.1007/s10347019-0561-8

Received in 14 February, 2019; accepted in 09 August, 2019. 